\title{
Universal Values based Human Resource Development Model
}

\author{
Sunil Garg \\ Department of Humanities, Hindustan College of Science and Technology, Mathura, UP, India
}

\begin{abstract}
Purpose - This research aims to answer the questions for more empirical research on identity theory by exploring the role of training and impact of human resource development (HRD) system, and to find out the gap between HRD practice and holistic approach in organizations

Design/methodology/approach - This study uses ethnomethodology, phenomenology and self exploration method.

Findings - The research found a gap between current training module and needs to set HRD practices according to universal human values approach and suggest model to fulfill the same. It found a gap between policy and practice has one or two dimensional approach instead of holistic perception. This gap is because of lack of understanding and awareness.

Research limitations/implications - This paper used ethnomethodology, phenomenology and self exploration method, which may vary from person to person during interpretations. These method based on exploration and collection of data from day - to-day events which higly depend on observer. Further research is required to confirm these results using several data sources.

Practical implications - Managers and HRD functions should increase both soft policy and soft practice and ensure there is no gap between policy and practice. To achieve this, organizations should ensure that the HRM function is both strategic and effectively resourced.

Originality/value - This research makes a theoretical and empirical contribution to debates on the role that HRD practices play in organizations. It also adds value to HRM research and practice.

Keywords: Human values; HRD Model; Universal Values; Harmony, Human Resource Management, Ethics
\end{abstract}

\section{Introduction}

Rokeach (1973), defined an attitude as an organization of several beliefs focused on a specific object or situation whereas a value is an enduring belief in a specific mode of conduct or desirable end state of existence. A number of research studies demonstrate that attitudes and values are different constructs, not only in the minds of researchers, but also in the minds of practitioners (Hofstede, 1998).Values are essence of life .Values is like the building blocks which are used to form a firm structure. The building blocks are set into position by several workers to construct a building. In the same way, the values inherited from family, society, environment, culture and other influencing factors, if rightly placed, then they raise up a firm individual ( Vaishali R. Khosla, Kavita Bhagat-2012) .

New approach of "Human Values and Professional Ethics", has successfully launched in various universities as a subject and has emerged as a new and a practical concept which can improve the performance of worker and ensure right understanding in them. The concept was successfully experimented for a number of years. In the form of seven day workshops, this input has been experimented very extensively with all spectra of people in the society. The experiment conducted at IIIT Hyderabad, IIT Delhi, IIT Kanpur, NIT Raipur and Somaiya Vidhyavihar, Mumbai, etc are worth mentioning. Recently UP technical University, Punjab Technical University etc has accepted this concept as a full course to teach the students. It has been noticed a tangible change in the thinking of students, in terms of their vision about happiness and prosperity, the clarity about life goals, improvement in human relationship, self confidence, commitment to learning, feeling more responsible towards the profession, etc.

According to David and Stephen (2002) HRD function can be viewed along three dimensions. The first is employee training, which emphasizes skills development and the changing attitudes among workers . The second is management development, which concerns it's primarily with knowledge acquisition and the enhancement of an executive's conceptual abilities. The third is career development, which is the continual effort to match long-term individual and organizational needs.

\section{Literature Review}

Imagine that firm performance, especially worker efficiency, will be impacted by the choice of HRM for given a skill, where technology is characterized by increase in efficiency, reduction in products rate and large scale production .Even though concerns, along with so many speaker, had but a faint fear of what might be possible in the business world when organizations got it wrong. The proceedings of the succeeding months 
verified to all the level of risk that exists. The questions is that everyone in the field of Human Resource management ask today,

- Did organizations fail not just despite of their HR, but because of their HR policy?

- How does the sustainability of HR affect the HR - position of organizations?

- How can it assist in the building of strategic capability?

- What might this strategic capability look like?

Significant changes in behavior of can be brought by developing proper understanding about the definiteness in human conduct. These can be possible only by process of self exploration and self actualization. As we all know that changes in individual can be brought about if those who are expected to change are able to participate in deciding what the changes will be. This organizational principle is very popular in the 1990s, with many organizations introducing attitude surveys to see what employees think. Sadly many companies do not appreciate this point.

\subsection{Human Resource Development}

HRD function is different from personnel/HRM functions. Rao (2007) outlines the following roles of an HRD manager:

- Developing enabling capabilities in individuals and the system.

- Integrating the development of the people with organizational development.

- Maximizing the learning opportunities of individuals in organizations through various mechanisms, autonomy and responsibility.

- Decentralization, delegation and shared responsibility.

- Balancing change and adaptation.

- Building feedback and reinforcement mechanisms, etc.

\& Stephen -2002 defined "Management development is more future oriented and more concerned with education, than is employee training, or assisting a person to become a better performer. By education, we mean that management development activities, attempt to instill sound reasoning processes - to enhance one's ability to understand and interpret knowledge -rather than imparting a body of serial facts or teaching a specific set of motor skills. Development therefore focuses more on the employee's personal growth".

There is a relationship between happiness and prosperity and among employees to achieve organizational objectives. Mind Tools Ltd -2008, in the study with title " Career Skills \& Workplace Happiness" define in an international survey of 10,310 people in 131 countries (including 3423 in the US, 1290 in the UK, and 1082 in India), looking at the relationship between people's skills levels and a number of factors, including workplace happiness. Happiness is important because it strongly affects employee performance, and because it affects organizations' ability to retain staff. This is vital, given a projected $19 \%$ decline in the number of people between 35 and 44 in the US and UK workforces within the next 5 years. Key survey findings are $66.3 \%$ of people who were happy in their job were confident in their stress management skills. Only $42.4 \%$ of people who were not happy are similarly confident. This is a difference of $23.9 \%$. There was an average confidence difference of $11.6 \%$ between people who are happy at work and those who are unhappy, across nine other skills areas (time management, team management, leadership, communication, team-working, decisionmaking, problem-solving, project management and change management).

What this means is that people with good stress management skills are very much more likely to be happy at work. It also means that people with good career skills are much more likely to be happy at work than those with weaker skills. Managers should strongly consider training their staff in stress management and other career skills if they want to improve workplace happiness. (Mind Tools ltd - 2008). This study tries to focus to recognize the role of Universal Human Values in HRM practices for the development of new HRM Manual \& practices. HRM has been developed from personnel management by considering the policy of an organization from Human focused approach, primarily on the hiring and firing of people. In an organization individual work together; there they contribute to the objectives of the business. The development of any practice highly based on personal growth, but when we understand that the universal acceptable values, then only it becomes science or subject to teach. "Kireet Joshi (2010) in the article - "Challenges in introducing Value Education at Higher Education in India writes that the necessity for imparting values to the persons of all levels has been felt by everyone. Today, the world is facing unprecedented socio-political and economic challenges troubles of life are becoming increasingly strong and complex. Traditional values are de-centered. An environment of strife pervades all countries and broken homes have become common". Now-a-days everyone is busy in money making involving them in with full motivation and devotion for developing skills, persons are focusing them in rat race of physical world. The long history of mankind has seen a lot of progress. Science has enabled us to improve human understanding of the physical reality around them. Implementation of HRM systems is more important than individual characteristics because there are synergies and complementarities in HRM practices , 
but there is need of development of system highly paying attention on individual happiness and prosperity. Many Researches highlighted that motivated and happy people work more effectively than other.

\section{Methodology}

The main goal of this research is to explore a universal model of human development's through the process of self exploration and self investigation. This research is an applied one with regard to the kind and nature, the research and is conducted using a Ethnomethodology and phenomenological sociology method.

\subsection{Ethnomethodology}

Ethnomethodology studies mainly those sides or dimensions of human behavior which are related to day to-day activities of life. According to Garfinkel (1950), ethnomethodology state that " a sociologist has to study how day-to-day activities and behavioral situations are interrelated, how it seems, how to collect their information and how a different person understand these in series". Garfinkel (1954) states , "Ethnomethodology studies folk or studies daily activities method which is related to construction of social realities and focuses on societal inter-related activities and social structure which are invariant to change the social institutions". Supporter of ethnomethodology believes that it explains existence or world and how we understand it. Ethnomethodology developed through symbolic interactions and principle of phenomenology. Hence, it explores dimensions of those subjects which are related to micro and macro analysis and does not consider different principles.

\subsection{Phenomenological Sociology or Phenomenology}

Phenomenology was propounded by German Philosopher Edmund Husseral in contemporary era. This is also a philosophical method. It studies consciousness purely and to understand social realities and emphasizes on subjective human consciousness. It is substitute of Positivist methodology defines that social realities are different from natural realities; hence it cannot be explain exterior structure and expressions but can be understand by knowing hidden meaning of action and reaction, human attitudes, human emotions, sensations, human feelings, etc.

According to Alfred schutz (1945), phenomenology has two main aspects. "Every human has few thought structures nerves and all worldly phenomenon explanations are based on these nerves. The more personal the relationship the more unique is its character bound to be; the more impersonal the relationship the more typified. Every individual sees his or her social situation according to his or her perspectives and try to comprehend it, according to favorable and non -favorable setting he or she defines relations". Hence phenomenology has two magnitudes first one, what we understand about things or social realities and second, how we comprehend things or social realities. Phenomenology is not a new doctrine and many thinkers worked on it. Competencies are centered on the individual, but constructivist and interpretative approaches derived from phenomenology view competence as a function of the context in which it is applied (Dreyfus and Dreyfus 1986).Qualitative research is concerned with explaining the meaning of human interactions and with exploring individuals' interpretations and beliefs, and when meaning is involved phenomenology is the method that best answers the research question (Denzin and Lincoln, 1998). Therefore, phenomenology was used as the research methodology for this study.

\subsection{Self Exploration}

Self exploration is the process to find out what is valuable to person by investigating within himself, what is right for him, true for him, has to be judged within himself. Through self exploration he get the value of himself. Person live with different entisrety (family, friends, air, soil, water, trees, etc.) and want to understand his relationship with all these. For this he need to start observing inside according to R.R.Gaur, R. Sangal , G.P. Bagaria (2010).

\section{Basic guidelines for Universal Value based HRD Model.}

Value based Human Resource Development has to enable person to be in harmony within and in harmony with other. Hence, when person live on the basis of these values, person start understanding that it will lead to harmony in human beings, and harmony in interactions with humans and the rest of the nature. ( R.R.Gaur, R. Sangal , G.P. Bagaria -2010). Presently existing HRM model focused to implement policies which contribute towards the better working ambiance and satisfaction with management policy in the organization. This model focused about the development of right understanding in individual thought, behavior, work and realization. 


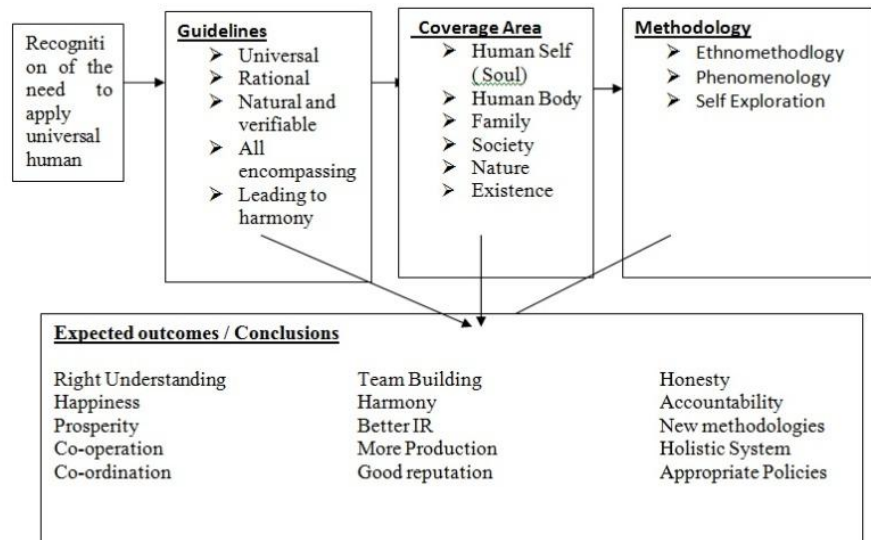

4.1Basic guidelines for Universal human Values based Human Resource Develpment Model

Given below are broad guidelines to decide on what would qualify as an appropriate input in this model.

\subsubsection{Universal, secular, non-sectarian}

Whatever we understand as values for Human Resource Management has to be universally applicable to all human beings and be true at all times and all places. In addition, it need not restrict itself to a certain sect, creed, gender or nationality etc. So it has to deal with universal human values. Hence the model focus on inculcating value based living, which is universally acceptable and applicable to all human being. Like Newtons Law in Physics are universally verified.

\subsubsection{Rational-appeals to human reasoning}

It has to amenable to reasoning and not based on dogmas or blind beliefs. It cannot be a set of sermons or Do's or Don'ts. It should be logical in nature and broadly acceptable to all human being and this can be done by both checking the validity within the person himself and its applicability to other human being naturally.

\subsubsection{Natural and verifiable}

Being natural means, it is acceptable in natural manner to all human beings. When person live on the basis of such values that are natural to him, it leads to fulfilment, leads to happiness and also is conducive to other people interact with them, as well as nature. Person assume something just because it is being stated here or written in a book, rather, each one of them have will want to verify these to find out whether they are true for all human being .No contradictions between goals. e.g. relationship at home, opposition outside or within the organizational level or management or workers relations.

\subsubsection{All Encompassing}

Covers the full expanse of living i.e.

5 levels -Individual, Family, Society, Nature, Existence

4 dimensions - Thought, Behavior, Work, Realization

Value model is not merely an academic exercise. It is aimed at transforming consciousness and living. Hence, it has to permeate into all dimensions of living namely, thought, behavior, work and understanding / realization; as well as all levels , namely, individually, family, society and nature.

\subsubsection{Leading to Harmony}

This model enble person to be in harmony within and in harmony with others.Hence the person lives on the basis of these values and harmony in interactions with other human and rest of the nature and covers the full expanse of living i.e.

5 Levels - Individual, Family, Society, Nature, Existence

4 Dimensions - Thought, Behavior, Work, Realization

\section{Coverage Area}

Each person lives at the level of Human self, Human Body, Family, Society , Nature and existence whther a person aware or not. All these levels of living need to be investigated into. If a person look into himself and identify various activities - choices, thoughts and desires. This will help him how he think, and what he want. He will identify how and why he get easily influenced by others, by things or by reading. Person look into relationship with relationship with others ( starting from the family) and understand what the expectations in human relationships are, whether there can be identified, and fulfilled. As a result, it becomes possible to 
identify why the person have problem in human relationship today. Now look into various dimensions of human society, what the comprehensive human goal is, and how this can be achieved. Finally, take the study of nature / existence : and understand the interconnectedness in nature, and the role / participation of person in totality that exists.

Today we are generally trying to achieve happiness and prosperity by maximizing accumulation and consumption of physical facilities. This effort is giving rise to many problems manifest today at thelevel of individual, family, society and the nature. These problems are:

\subsection{At the level of individual}

Rising problems of depression, anxiety, suicides, stress, insecurity, increasing health problems, lack of confidence and conviction etc.

\subsection{At the level of family}

Breaking up of joint families, mistrust and disharmony in relationships,divorce, generation gap, dowry deaths, neglect of older people etc.

\subsection{At the level of society}

Growing incidences of terrorism, violence, communalism, racial and ethnic struggle, corruption, adulteration, sex-crimes exploitation, wars between nations, proliferation of lethal weapons etc.

\subsection{At the level of nature / Existence}

Global warming, weather imbalances, depletion of mineral and energy resources, deforestation, soil degradation etc. All the problems are a direct outcome of an incorrect understanding, wrong notion about happiness and prosperity and their continuity.

\section{The Holistic Criteria for Evaluation of HRD model}

The modern technologies and systems are all human inventions in response to the needs visualized under the influence of the prevailing worldview. Accordingly, they have been designed and optimized to the objective functions best suited to this world view. In order to facilitate the development of holistic technologies and systems, it will be necessary to visualize alternative objective functions and to formulate appropriate criteria for evaluation compatible with comprehensive human goal. Generally speaking, there are three broad criteria to guide the development of such technologies and systems, viz.

(1) Catering appropriate needs and lifestyles,

(2) People-friendly, and

(3) Eco- friendly.

\subsection{Naturally acceptable}

(1) Experientially verifiable in behaviour, work .

(2) Leading to harmony with humanity and harmony with nature

(3) Conducted without preaching.

Person are encouraged to question, disagree, discuss, validate for themselves on their own right.

The recent opportunity for disruptive technologies to create new ways of competing has seen the issue of business model change start to dominate the attention of business leaders. Business Model Innovation (BMI) has now become an area of separate strategic attention. Clayton Christensen and colleagues 27 have drawn attention to the nature of disruptive innovation - where a new customer paradigm or technology enables new entrants to capture market share and create new markets. They have used theories of innovation to help explain the role played by business model innovation and distinguished two types of innovative technology.Sustaining technologies, which improve existing products or services, and Disruptive technologies, which completely change the nature of a market or business.

\subsection{Exploring Happiness and Prosperity correctly 6.2.1 Happiness}

"The state /situation in which person live, if there is harmony/synergy in it, and then person like to be in that state or situation." Or "To be in a state of liking is happiness."

When a person in such a state of happiness - he/she experiences no struggle, no contradiction or conflict within and enjoy such a state of being harmony and wish to have its continuity.

\subsubsection{Unhappiness}

"The state/situation in which person live, if there is conflict / contradiction in it, and he do not like to be in that state or situation." Or "To be in a state of disliking is unhappiness." 
On the other hand, when person experience feeling such as failure, disrespect, lack of confidence, being doubtful in themselves or about other, person feel unhappy. These are the states when there is lack of harmony, either within person themselves or between him and others.

\subsubsection{Prosperity}

It is the feeling of having or making available more than required physical facilities. To ascertain prosperity, two things are essential:

(a) Correct assessment of need for physical facilities, and

(b) The competence of making available more than required physical facilities (through production).

It is easy to see that prosperity is related to material things or known as 'physical facilities'.

\section{Conclusion}

Presently, all human policies, programs, technologies and professions, as well as economic, political and social systems have evolved to best cater to the prevailing worldview - which is seriously in error. Therefore, all these will need to be gradually modified to suit the holistic worldview, to suit right understanding and comprehensive human goal. This may be gradual process and will depend on the extent to which society is able to imbibe the new ethos.

Another important step for bringing about the requisite transition is to provide adequate trust for carrying out Research and Development towards evolving holistic models of living which include development of holistic human resource management models to actualize the holistic way of life. Presently, the trend in our institutions and research laboratories is largely towards working on various fashionable research areas advocated by those who have pioneered the modern development and whom we have accepted as "role model". However, after being amply clears that the present model is not sustainable and not conducive to comprehensive human resource development model in the light of right understanding.

To ensure happiness and prosperity and their continuity to all human beings, the transition to human consciousness is essential. This requires a dedicated effort to implement at mass scale, the humanistic education and training focusing on right understanding. It can be initiated by introduction of appropriate value education inputs in the present Human resource development model and in training curricula. The urgency of this task has to adequately realize and accordingly efforts are to be made commensurate with need. The evolution at the personal level has been given priority. Further, efforts are also to be directed towards evolving the new models for holistic alternatives and appropriate policies, programs and systems.

It will be critically examine the characteristic of the present models which have been developed under the materialistic worldview. The most concerning feature of the present day systems is their heavy dependence on mass production skills and training. This has caused menace of resource depletion on one hand and environmental degradation manifesting in the form of pollution and global warming etc. on the other. There is no compatibility with the rate of consumption and the rate production in Nature. The other undesirable characteristics of modern technologies and systems include their centralized configurations, promotion of wastefulness, excessive transportation and substitution of human, animal and other natural resources.

\section{References:}

[1] Alfred Schutz (1945), "Studies in phenomenological Philosophy", pp- 65.

[2] Alfred Schutz (1948), "Phenomenology of the Social World",pp- 127.

[3] David A. DeCenzo \& Stephen P. Robbins (2002), "Chapter 1, Introduction to HRM", Personnel / Human Resource Management, $3^{\text {rd }}$ Ed", pp. 5,253

[4] Denzin, N.K. and Lincoln, Y.S. (1998), "Introduction: entering the field of qualitative research", in Denzin, N.K. and Lincoln, Y.S. (Eds), Strategies of Qualitative Inquiry, Sage, Thousand Oaks, CA, pp. 1-15.

[5] Dreyfus, H. L., and Dreyfus, S. E. (1986) Mind over Machine: The Power of Human Intuition and Expertise in the Era of the Computer. New York: Free Press.

[6] Harold Garfinkel (1950), "Studies in Ethnomethodology",pp-45.

[7] Harold Garfinkel (1954), "Contribution to Ethnomethodology”,pp-20.

[8] Hofstede, G. (1998), “Attitudes values and organizational culture: disentangling the concepts”, Organization Studies, Vol. 19, pp. 477-92. http://www.informaworld.com.

[9] Kireet Joshi, Philosophy of Value Oriented Education Theory and Practice, ICPR Publications, New Delhi, pp. 217. www.mindtools.com

[10] Rao, T.V. (2007), "Is it time to replace HRD managers by knowledge and learning managers?" available at: http//indianmba.com/ Faculty Column /FC525/fc525.html (accessed 23 March 2007) Rokeach, M. (1973), Nature of Human Values, Free Press, New York.

[11] R.R.Gaur, R. Sangal , G.P. Bagaria (2010), Human Values and Professional Ethics, $1^{\text {st }}$ Ed , pp.7,11,205, 254-255, Vaishali R. Khosla, Kavita Bhagat-2012- Human Values and Professional Ethics, pp-12 Corresponding author 